\title{
Survival benefit of gastrectomy \pm metastasectomy in patients with metastatic gastric cancer receiving chemotherapy
}

\author{
Ki Hwan Kim $\cdot$ Keun-Wook Lee $\cdot$ Sun Kyung Baek $\cdot$ \\ Hye Jung Chang $\cdot$ Yu Jung Kim $\cdot$ Do Joong Park • \\ Jee Hyun Kim · Hyung-Ho Kim · Jong Seok Lee
}

Received: 21 July 2010/Accepted: 16 November 2010/Published online: 4 March 2011

(c) The International Gastric Cancer Association and The Japanese Gastric Cancer Association 2011

\begin{abstract}
Background This study was performed to investigate the role of surgery in patients with gastric cancer and distant metastases who had received systemic chemotherapy.

Methods Patients with newly diagnosed gastric cancer and synchronous distant metastases who had received chemotherapy $(n=274)$ were categorized into 3 groups according to the surgical treatment rendered: complete gross resection of both primary and metastatic sites (group A; $n=42$ ); debulking gastrectomy (group $\mathrm{B} ; n=47$ ); and chemotherapy without debulking (group C; $n=185$ ).

Results The median overall survival of all patients was 11.8 months. The median overall survival and 3-year survival rates were 28.0, 15.5, and 9.0 months and 42.8, 8.1, and $3.5 \%$ in groups $\mathrm{A}, \mathrm{B}$, and $\mathrm{C}$, respectively. In group A, patients with peritoneal seeding, intra-abdominal distant lymph nodes, or ovarian or hepatic metastases underwent complete gross resection, and $12(29 \%)$ were disease-free at the time of the last analysis (median follow-up duration, 29.1 months). On multivariate analysis, the adjusted hazard ratios for death were $0.27 \quad(P<0.001)$ and 0.64 $(P=0.024)$ for groups A and $\mathrm{B}$, respectively, as compared to group $\mathrm{C}$.
\end{abstract}

The institution at which the work was performed: Seoul National University Bundang Hospital.

K. H. Kim · K.-W. Lee $(\bowtie) \cdot$ S. K. Baek ·

H. J. Chang - Y. J. Kim - J. H. Kim - J. S. Lee

Department of Internal Medicine, Seoul National University

Bundang Hospital, 300 Gumi-dong, Bundang-gu, Seongnam-si,

Gyeonggi-do 463-707, Republic of Korea

e-mail: hmodoctor@hanmail.net

D. J. Park · H.-H. Kim

Department of Surgery, Seoul National University Bundang

Hospital, Seongnam, Republic of Korea
Conclusions Our study suggests survival benefits of debulking gastrectomy or gastrectomy plus metastasectomy in gastric cancer patients with distant metastases receiving systemic chemotherapy. Prolonged disease-free survival was observed after complete resection (gastrectomy plus metastasectomy) that may lead to cure in some patients. Well-designed prospective trials of the role of multidisciplinary approaches combining chemotherapy and surgery are needed to confirm the observations of our study.

Keywords Stomach cancer - Metastasis - Debulking gastrectomy $\cdot$ Metastasectomy

\section{Introduction}

In spite of its decreasing incidence and mortality, gastric cancer (GC) is the second most common cause of cancer deaths worldwide [1]. GC mortality has remained high due to the frequent initial presentation with distant metastasis. Although surgery is mandatory for the cure of locoregional $\mathrm{GC}$, the role of surgery for metastatic gastric cancer (MGC) is controversial [2-18]. For patients with MGC, palliative chemotherapy and best supportive care are considered the only standard treatment to achieve extension of survival and palliation of symptoms [19]. By these means, however, the outcome has been very poor, with a median overall survival (OS) of $<1$ year [20,21].

Recently, some retrospective studies have shown significant survival benefits for palliative debulking gastrectomy in patients with MGC [11, 13-18]. Based on these results, some experts insist that debulking gastrectomy is the preferred choice for patients with MGC before the initiation of chemotherapy. In addition, there have been 
some studies of gastrectomy plus metastasectomy for patients with MGC [4-10]. However, the role of metastasectomy is also controversial, as is that of debulking gastrectomy, because previous studies with small sample sizes have shown various outcomes, with a median OS of 11.2-31.0 months [4-10]. Moreover, most previous studies evaluating the benefit of gastrectomy \pm metastasectomy in MGC were performed without considering the effect of systemic chemotherapy-the only proven standard treatment in MGC [19] — and thus both patients who had and had not received systemic chemotherapy were included [3$6,8-18$ ]; this has made many clinicians confused about the real benefits of surgery in MGC.

Against this background, we investigated the effect of gastrectomy \pm metastasectomy on survival outcomes in patients with MGC who had received chemotherapy.

\section{Patients and methods}

\section{Patients}

This study used two comprehensive databases (the electronic medical record [EMR] database and the GC database of Seoul National University Bundang Hospital [SNUBH]). SNUBH is the first university hospital which has a fully digitalized system, including EMR, in Korea. The two databases contain information collected prospectively on all consecutive GC patients since the opening of SNUBH in May 2003 [22].

Between May 2003 and May 2008, the number of patients who had pathologically confirmed adenocarcinoma of the stomach was 2283. Patients with locoregional GC at the time of GC diagnosis ( $n=1915$; stages I, II, III, and IV $\left(\mathrm{M}_{0}\left[\mathrm{~T}_{4} \mathrm{~N}_{1-2} \mathrm{M}_{0}\right.\right.$ or $\left.\left.\mathrm{T}_{\mathrm{X}} \mathrm{N}_{3} \mathrm{M}_{0}\right]\right)$ according to the staging manual of the American Joint Committee on Cancer [AJCC, 6th edition]) were excluded [23]. Among 368 patients with synchronous distant metastasis (stage IV $\left(\mathrm{M}_{1}\right)$ ) at the time of GC diagnosis, 94 patients who had never received chemotherapy were also excluded. Therefore, 274 patients with GC and synchronous distant metastases at the time of GC diagnosis who had received chemotherapy were included in this study.

Data on age, gender, Eastern Cooperative Oncology Group (ECOG) performance status (PS), primary tumor location, pathological differentiation, the number of organs involved by GC, chemotherapy, and surgery were retrieved from the two databases. The number of organs involved by GC was counted according to the presence of cancer in the following organs: $\mathrm{T}_{4}(\mathrm{~T}$, direct invasion into an adjacent organ), distant lymph nodes $(\mathrm{N})$, liver $(\mathrm{H})$, lung $(\mathrm{L})$, peritoneal seeding nodules $(\mathrm{P})$, bone $(\mathrm{B})$, and other distant organs (O). This study was approved by the Institutional
Review Board. The recommendations of the Declaration of Helsinki for biomedical research involving human subjects were followed throughout.

Surgical procedures and outcomes

For stage evaluation, abdominal computed tomography (CT) and chest X-ray were routinely performed. Surgery (gastrectomy \pm metastasectomy) was only considered in patients with adequate organ function and acceptable ECOG PS (grade $\leq 2$ ). Patients with extensive tumor burdens (i.e., extensive peritoneal or liver metastasis) were not candidates for gastrectomy ( \pm metastasectomy). With the exception of patients with severe symptoms (obstruction, perforation, or bleeding) directly caused by gastric cancer per se, only patients with the number of organs involved by GC of $\leq 2$ were considered for gastrectomy ( \pm metastasectomy).

When the baseline CT showed resectable or borderline resectable extent of tumor burden in regard to the technical aspects of surgery, laparoscopy was performed preoperatively in all these patients. If the tumor extent seemed to be completely resectable according to the laparoscopic findings, open laparotomy was performed to achieve complete gross resection (CGR) of both the primary and metastatic sites. However, if the tumor burden was beyond that expected according to the preoperative laparoscopy findings compared with the CT findings, and thus CGR was not feasible, palliative debulking surgery followed by chemotherapy or primary chemotherapy without surgery was performed.

In the analysis, patients were classified into 3 groups according to the surgical outcomes for the primary or metastatic sites of GC. The first group included patients who had undergone CGR of both the primary and metastatic sites (group A). The second group (group B) consisted of patients who had undergone palliative debulking gastrectomy for the purpose of tumor reduction or symptom palliation without metastasectomy. Patients who had undergone incomplete resection for primary or metastatic sites (gross residual disease [R2] or microscopic residual disease [R1] in the postoperative pathology report) were also classified as group B. The third group included patients who had been treated with chemotherapy alone or chemotherapy plus non-debulking surgery, such as explorative laparotomy/laparoscopy or bypass surgery (group C).

CGR of the metastatic tumor was defined as follows: complete removal of hepatic metastasis by surgery or radiofrequency ablation in cases of liver metastasis; peritonectomy of peritoneal seeding nodules, which were classified as P1 (metastases to the adjacent peritoneum, such as the lesser sac, and lesser or greater omentum, but 
not to the distant peritoneum) or P2 (a few to several scattered metastases to the distant peritoneum) by the Japanese classification of gastric carcinoma (first English edition) and were considered to have been completely removed by surgeons [24]; resection of ovaries in cases of Krukenberg tumors; and lymphadenectomy with free pathological margins in cases of intraabdominal distant lymph node metastases. With respect to the primary tumor site, D2 or D3 perigastric lymph node dissection was mandatory for a procedure to be classified as CGR. Only patients who had undergone CGR for both the primary and metastatic sites were classified into group A. However, patients who had received less than D2 perigastric lymph node dissection or had residual disease ( $\mathrm{R} 1$ or $\mathrm{R} 2$ ) for primary or metastatic sites were not considered to have undergone CGR and were classified into group B.

\section{Statistical analysis}

Statistical analysis was performed using SPSS 13.0 for Windows (SPSS, Chicago, IL, USA). The $\chi^{2}$ test was performed to compare percentages in cross-tabulations. The OS and disease-free survival (DFS) were calculated using the Kaplan-Meier method. OS was measured from the date of initial pathology-confirmed GC diagnosis to the date of death from any cause. In group A, DFS was calculated from the date of CGR for both the primary and metastatic sites to the date of the first observation of cancer recurrence or the date of death from any cause. Univariate analysis for OS was performed using the log-rank test. Multivariate analysis for prognostic factors was conducted with the Cox proportional hazards model. A value of $P<0.05$ by the twosided test was considered statistically significant.

\section{Results}

\section{Patient characteristics}

There were 42, 47, and 185 patients in groups A, B, and C, respectively. The patient characteristics and the treatments rendered to enrolled patients are summarized in Table 1 . The median age was 61 years (range, 21-89 years) and approximately two-thirds of the patients were males. Peritoneal seeding was the most common site of metastasis (63\%), followed by intraabdominal distant lymph nodes (44\%) and liver (26\%). More than 2 organs were involved by GC in $19 \%$ of the patients. In group A $(n=42), 36$ patients received initial surgery for both the primary and metastatic sites; among these patients, chemotherapy was immediately initiated after recovery from the surgery in 35 patients and chemotherapy was administered after confirmation of tumor recurrence in 1 patient. Initial chemotherapy followed by CGR of both the primary and metastatic sites was performed in the remaining 6 patients. In group B $(n=47), 45$ patients underwent initial debulking gastrectomy; chemotherapy was immediately introduced after surgery in 42 patients and chemotherapy was administered after the progression of residual tumors in 3 patients. Initial chemotherapy followed by surgery was performed in the remaining 2 patients; although the tumors in these 2 patients had shown a response to the initial chemotherapy, and thus surgery with the intent of complete resection of both the primary and metastatic sites was attempted; CGR was not possible, and therefore these 2 patients were classified into group B. In group C ( $n=185), 34$ patients underwent bypass or explorative surgery without tumor debulking.

\section{Descriptions of surgery performed in groups A and B}

In group A $(n=42)$, distant metastases were identified prior to surgery by abdominal CT in 19 patients and unexpected metastases were detected during surgery in 23 patients; peritoneal seeding nodules $(n=19)$ and distant lymph nodes ( $n=19$ ) were the most common sites of resection, followed by the liver $(n=4)$ and ovaries $(n=4)$. All patients in group A had the number of organs involved by GC of $\leq 2$. All patients in group A underwent D2 or D3 dissection of lymph nodes. D3 lymph node dissection was applied to selected cases with enlarged distant lymph nodes that seemed to be resectable. Six patients with peritoneal seeding were treated with intraperitoneal chemotherapy using 5-fluorouracil; hyperthermia was not used.

In group B $(n=47), 21$ patients received debulking surgery for symptom palliation (i.e., obstruction, perforation, or bleeding); of these 21 patients, 17 patients had the number of involved organs of $\leq 2$ and 4 patients had 3 organs involved. The other 26 patients, who did not have obvious symptoms caused by GC, received debulking gastrectomy; in all these 26 patients, the number of involved organs was $\leq 2$.

The descriptions of surgery and the postoperative complications in groups A and B are presented in Table 2. Surgery-associated complications, including wound infections, mechanical ileus, and leakage, were not serious in most cases and no surgery-related mortality developed. The median postoperative duration of hospital stay was 13 and 12 days in groups $\mathrm{A}$ and $\mathrm{B}(P=0.066)$. One patient in group A underwent redo-surgery for metastasectomy of the lung during the follow-up period, and one patient in group $B$ underwent redo-surgery for resection of the transverse colon due to progression of the tumor.

Survival outcomes according to the surgical treatment applied

As of January 2009, the median duration of follow-up of all patients and 43 patients who were alive at the time of the 
Table 1 Patient characteristics and treatments applied in enrolled MGC patients

\begin{tabular}{|c|c|c|c|c|}
\hline Characteristics & $\begin{array}{l}\text { All patients }(n=274) \\
\text { Number }(\%)\end{array}$ & $\begin{array}{l}\text { Group A }(n=42) \\
\text { Number }(\%)\end{array}$ & $\begin{array}{l}\text { Group B }(n=47) \\
\text { Number }(\%)\end{array}$ & $\begin{array}{l}\text { Group C }(n=185) \\
\text { Number }(\%)\end{array}$ \\
\hline \multicolumn{5}{|l|}{ Age (years) } \\
\hline Median & 61 & 60 & 61 & 61 \\
\hline Range & $21-89$ & $31-80$ & $27-89$ & $21-85$ \\
\hline \multicolumn{5}{|l|}{ Gender } \\
\hline Male & $192(70)$ & $24(57)$ & 37 (79) & $131(71)$ \\
\hline Female & $82(30)$ & $18(43)$ & $10(21)$ & $54(29)$ \\
\hline \multicolumn{5}{|l|}{ Performance status } \\
\hline ECOG $0-1$ & $204(74)$ & $38(90)$ & $34(72)$ & $132(71)$ \\
\hline $\mathrm{ECOG} \geq 2$ & $70(26)$ & $4(10)$ & $13(28)$ & $53(29)$ \\
\hline \multicolumn{5}{|l|}{ Primary tumor location } \\
\hline Upper one-third & $53(19)$ & $12(29)$ & $7(15)$ & $34(18)$ \\
\hline Middle or lower one-third & $198(72)$ & $25(59)$ & $35(74)$ & $138(75)$ \\
\hline Entire stomach & $21(8)$ & $5(12)$ & $5(11)$ & $11(6)$ \\
\hline Unclassified & $2(1)$ & $0(0)$ & $0(0)$ & $2(1)$ \\
\hline \multicolumn{5}{|l|}{ Borrmann type } \\
\hline I & $8(3)$ & $1(2)$ & $1(2)$ & $6(3)$ \\
\hline II & $23(8)$ & $3(7)$ & $1(2)$ & $19(10)$ \\
\hline III & $153(56)$ & $20(48)$ & $28(60)$ & $105(57)$ \\
\hline IV & $80(29)$ & $16(38)$ & $17(36)$ & $47(26)$ \\
\hline EGC-like or unclassified & $10(4)$ & $2(5)$ & $0(0)$ & $8(4)$ \\
\hline \multicolumn{5}{|l|}{ Differentiation } \\
\hline $\mathrm{W} / \mathrm{D}$ or $\mathrm{M} / \mathrm{D}$ & $66(24)$ & $12(29)$ & $10(21)$ & $44(24)$ \\
\hline $\mathrm{P} / \mathrm{D}$ & $138(51)$ & $23(55)$ & $29(62)$ & $86(46)$ \\
\hline $\mathrm{SRC}$ & $58(21)$ & $6(14)$ & $6(13)$ & $46(25)$ \\
\hline Unclassified & $12(4)$ & $1(2)$ & $2(4)$ & $9(5)$ \\
\hline \multicolumn{5}{|l|}{ Sites of metastasis } \\
\hline Peritoneal seeding nodules & $172(63)$ & $19(45)$ & $39(83)$ & $114(62)$ \\
\hline Intraabdominal distant lymph nodes & $120(44)$ & $19(45)$ & $17(36)$ & $84(45)$ \\
\hline Liver & $71(26)$ & $4(10)$ & $5(11)$ & $62(34)$ \\
\hline Lung & $24(9)$ & $0(0)$ & $1(2)$ & $23(12)$ \\
\hline Bone & $23(8)$ & $0(0)$ & $3(6)$ & $20(11)$ \\
\hline Others & $22(8)$ & $4(10)$ & $3(6)$ & $15(8)$ \\
\hline \multicolumn{5}{|l|}{ Number of organs involved by metastasis } \\
\hline 1 Organ & $139(51)$ & $33(79)$ & $28(60)$ & $78(42)$ \\
\hline 2 Organs & $83(30)$ & $9(21)$ & $15(32)$ & $59(32)$ \\
\hline$\geq 3$ Organs & $52(19)$ & $0(0)$ & $4(9)$ & $48(26)$ \\
\hline \multicolumn{5}{|l|}{ Chemotherapy regimens used as 1 st line } \\
\hline Fluoropyrimidine with platinum & $202(74)$ & $33(79)$ & $37(79)$ & $132(71)$ \\
\hline Fluoropyrimidine alone & $25(9)$ & $5(12)$ & $6(13)$ & $14(8)$ \\
\hline Others & $47(17)$ & $4(10)$ & $4(9)$ & $39(21)$ \\
\hline \multicolumn{5}{|c|}{ Number of chemotherapy regimens administered after diagnosis of MGC } \\
\hline 1 Regimen (1st-line chemotherapy only) & $99(36)$ & $14(33)$ & $24(51)$ & $61(33)$ \\
\hline$\geq 2$ Regimens ( $\geq 2$ nd-line therapy) & $175(64)$ & $28(67)$ & $23(49)$ & $124(67)$ \\
\hline
\end{tabular}

ECOG Eastern Cooperative Oncology Group, $E G C$ early gastric cancer, $M G C$ metastatic gastric cancer, $W / D$ well-differentiated adenocarcinoma, $M / D$ moderately differentiated adenocarcinoma, $P / D$ poorly differentiated adenocarcinoma, $S R C$ signet ring cell carcinoma 
Table 2 Comparison of surgical treatment applied and postoperative complications in groups $\mathrm{A}$ and $\mathrm{B}$

\begin{tabular}{|c|c|c|c|}
\hline Characteristics & $\begin{array}{l}\text { Group A } \\
(n=42) \\
\text { Number } \\
(\%)\end{array}$ & $\begin{array}{l}\text { Group B } \\
(n=47) \\
\text { Number } \\
(\%)\end{array}$ & $P$ value \\
\hline Type of gastrectomy & & & 0.078 \\
\hline Total gastrectomy & $23(55)$ & $17(36)$ & \\
\hline Subtotal gastrectomy & $19(45)$ & $30(64)$ & \\
\hline Lymph node dissection & & & $<0.001$ \\
\hline D0-D1 & $0(0)$ & $17(36)$ & \\
\hline D2-D3 & $42(100)$ & $30(64)$ & \\
\hline Combined resection & & & $<0.001$ \\
\hline No & $0(0)$ & $37(79)$ & \\
\hline Yes & $42(100)$ & $10(21)$ & \\
\hline Omentum/peritoneum $^{\mathrm{a}}$ & $18(43)^{\mathrm{a}}$ & $1(2)$ & \\
\hline $\begin{array}{l}\text { Intraabdominal distant } \\
\text { lymph nodes }\end{array}$ & $19(45)$ & $0(0)$ & \\
\hline Large bowel & $8(19)$ & $2(4)$ & \\
\hline Spleen & $7(17)$ & $3(6)$ & \\
\hline Ovary & $4(10)$ & $1(2)$ & \\
\hline Liver & $4(10)$ & $1(2)$ & \\
\hline Pancreas & $2(5)$ & $3(6)$ & \\
\hline Others & $3(7)$ & $1(2)$ & \\
\hline Operation-associated complications & & & 0.163 \\
\hline No & $33(79)$ & $42(89)$ & \\
\hline Yes & $9(21)$ & $5(11)$ & \\
\hline Wound infection & $5(12)$ & $4(9)$ & \\
\hline Mechanical ileus & $3(7)$ & $0(0)$ & \\
\hline Leakage & $1(2)$ & $0(0)$ & \\
\hline Bleeding & $0(0)$ & $1(2)$ & \\
\hline Others & $2(5)$ & $0(0)$ & \\
\hline $\begin{array}{l}\text { Postoperative hospital stay duration } \\
\text { (days) }\end{array}$ & & & 0.066 \\
\hline Median & 13 & 12 & \\
\hline Range & $6-79$ & $3-35$ & \\
\hline Redo-surgery for metastasectomy & $1(2)$ & $1(2)$ & \\
\hline
\end{tabular}

${ }^{a}$ One patient had peritoneal seeding nodules at the time of the initial explorative laparotomy. Clinical complete remission was obtained after chemotherapy and surgery with curative intent was attempted. At the time of surgery, as there were no visible peritoneal nodules, only a total gastrectomy with lymph node dissection was performed

last analysis was 10.2 months (range, 0.2-56.2 months) and 18.8 months (range, 8.1-56.2 months), respectively.

The median OS for all patients was 11.8 months (95\% confidence interval [CI], 9.7-13.8 months). During the follow-up, 18, 35, and 156 deaths were observed in groups A, B, and $\mathrm{C}$, respectively. The median OS times of patients in groups $\mathrm{A}, \mathrm{B}$, and $\mathrm{C}$ were 28.0 months $(95 \% \mathrm{CI}, 20.1-35.9$ months), 15.5 months (95\% CI, 10.2-20.8 months), and 9.0 months (95\% CI, 7.6-10.4 months), respectively

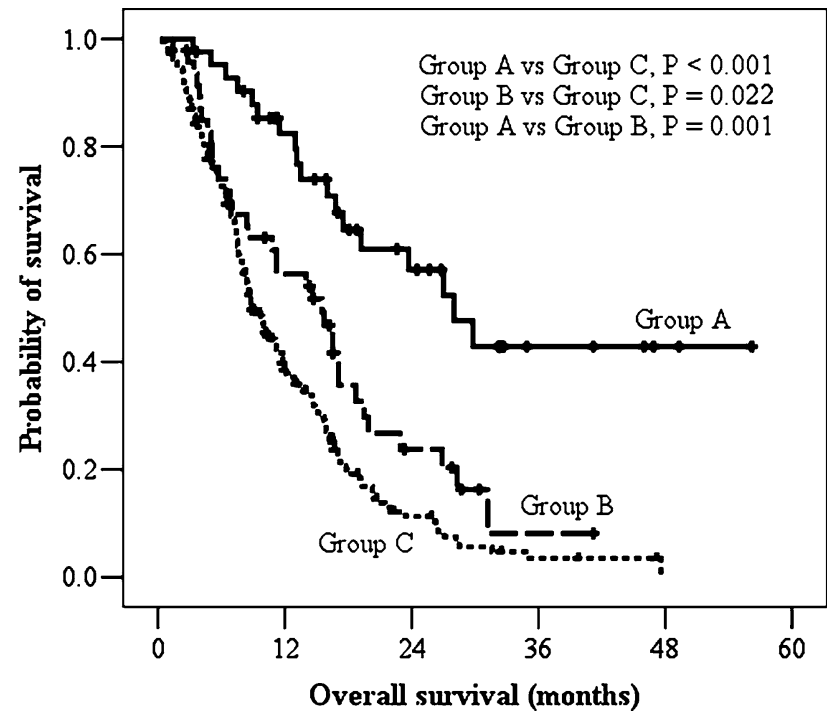

Fig. 1 Overall survival (OS) of patients with metastatic gastric cancer (MGC) treated with chemotherapy $(n=274)$, grouped according to surgical outcomes. Median OS times were 28.0, 15.5, and 9.0 months in groups $\mathrm{A}, \mathrm{B}$, and $\mathrm{C}$, respectively. Three-year OS rates were $42.8,8.1$, and $3.5 \%$ in groups $\mathrm{A}, \mathrm{B}$, and $\mathrm{C}$, respectively

(Fig. 1). The 3-year OS rates were $42.8,8.1$, and $3.5 \%$ in groups $\mathrm{A}, \mathrm{B}$, and $\mathrm{C}$, respectively. The median OS in groups $\mathrm{A}$ and $\mathrm{B}$ was significantly longer than that in group $\mathrm{C}$ ( $P$ values $<0.05)$.

Twelve patients in group A (29\%) were on regular follow-up without any evidence of tumor recurrence at the time of the last analysis (median duration of follow-up, 29.1 months [range, 8.1-56.2 months]; Table 3). The median DFS in group A was 11.0 months $(95 \% \mathrm{CI}$, 8.5-13.5 months).

\section{Analysis of prognostic factors for survival}

Univariate analysis, including parameters associated with the surgical treatment rendered and other clinical variables, was conducted and the results are presented in Table 4. On multivariate analysis using a Cox proportional hazard model, variables with associations with OS on univariate analysis $(P<0.05)$ were included and the 'enter' method was applied (Table 5). A good PS and upper one-third location of the primary tumor were significantly related to increased OS. The OS improvement in both group A (adjusted hazard ratio [aHR], 0.27; 95\% CI, 0.16-0.45; $P<0.001)$ and group B (aHR, 0.64; 95\% CI, 0.44-0.94; $P=0.024$ ) over group C was also significant in the multivariate model.

\section{Discussion}

Palliative treatment, including chemotherapy and best supportive care, is the primary treatment option for patients 
Table 3 Clinical characteristics and status of 12 patients who received CGR of primary plus metastatic sites and were on regular follow-up without any evidence of recurrence at the time of the last analysis

\begin{tabular}{|c|c|c|c|c|c|c|c|c|}
\hline Case no. & $\begin{array}{l}\text { Age } \\
\text { (years) }\end{array}$ & Gender & $\begin{array}{l}\text { ECOG } \\
\text { PS }\end{array}$ & Operation & $\begin{array}{l}\text { Metastatic } \\
\text { sites }\end{array}$ & $\begin{array}{l}\text { Chemotherapy } \\
\text { preop/postop }\end{array}$ & $\begin{array}{l}\text { Chemotherapy } \\
\text { (current status) }\end{array}$ & $\begin{array}{l}\text { Follow-up } \\
\text { duration (months) }\end{array}$ \\
\hline 1 & 65 & M & 1 & STG + distant lymphadenectomy & $\mathrm{N}$ & $\mathrm{NA} / \mathrm{F}+\mathrm{PL}$ & Off & 46.0 \\
\hline 2 & 80 & $\mathrm{~F}$ & 1 & STG + omentectomy & $\mathrm{P}$ & $\mathrm{NA} / \mathrm{F}$ & On & 24.5 \\
\hline 3 & 31 & $\mathrm{~F}$ & 1 & STG + peritonectomy & $\mathrm{P}$ & $\mathrm{NA} / \mathrm{F}+\mathrm{PL}$ & Off & 41.2 \\
\hline 4 & 51 & $\mathrm{~F}$ & 1 & $\mathrm{STG}+\mathrm{TAH} / \mathrm{BSO}$ & $\mathrm{O}$ & $\mathrm{NA} / \mathrm{F}+\mathrm{PL}$ & Off & 32.7 \\
\hline 5 & 63 & M & 1 & STG + distant lymphadenectomy & $\mathrm{N}$ & $\mathrm{NA} / \mathrm{F}+\mathrm{PL}$ & Off & 15.9 \\
\hline 6 & 64 & $\mathrm{~F}$ & 2 & STG + distant lymphadenectomy & $\mathrm{N}$ & $\mathrm{NA} / \mathrm{F}+\mathrm{PL}$ & On & 11.1 \\
\hline 7 & 46 & M & 1 & STG + hemicolectomy + omentectomy & $\mathrm{P}$ & $\mathrm{NA} / \mathrm{F}+\mathrm{PL}$ & On & 9.4 \\
\hline 8 & 52 & M & 1 & STG + peritonectomy & $\mathrm{P}$ & $\mathrm{NA} / \mathrm{F}+\mathrm{PL}$ & On & 8.1 \\
\hline 9 & 61 & M & 1 & $\mathrm{TG}^{\mathrm{a}}$ & $\mathrm{H}+\mathrm{P}$ & $\mathrm{F}+\mathrm{PL} / \mathrm{F}+\mathrm{PL}$ & Off & 56.2 \\
\hline 10 & 62 & M & 1 & $\mathrm{TG}+\mathrm{RFA}$ of liver metastasis & $\mathrm{H}$ & $\mathrm{T}+\mathrm{PL} / \mathrm{F}$ & Off & 46.9 \\
\hline 11 & 73 & M & 2 & STG + distant lymphadenectomy & $\mathrm{N}$ & $\mathrm{F}+\mathrm{PL} / \mathrm{No}$ & Off & 32.4 \\
\hline 12 & 65 & $\mathrm{~F}$ & 1 & STG + distant lymphadenectomy & $\mathrm{N}$ & $\mathrm{F}+\mathrm{PL} / \mathrm{F}+\mathrm{PL}$ & Off & 25.7 \\
\hline
\end{tabular}

CGR complete gross resection, ECOG Eastern Cooperative Oncology Group, PS performance status, STG subtotal gastrectomy, TG total gastrectomy, $T A H$ total abdominal hysterectomy, $B S O$ bilateral salphingo-oophorectomy, $N$ intraabdominal distant lymph node, $P$ peritoneal seeding, $O$ ovary, $H$ liver, $F$ fluoropyrimidine, $P L$ platinum, $T$ taxane, $N A$ not applicable

a This male patient had peritoneal seeding nodules at the time of the initial explorative laparotomy. After chemotherapy (5-fluorouracil + oxaliplatin), abdominal imaging and gastroscopy showed clinical complete remission, and surgery with curative intent was attempted. At the time of surgery, because there were no visible peritoneal nodules, only a TG, including lymph node dissection, was performed, and the pathological stage was ${ }^{\mathrm{yp}} \mathrm{T} 2 \mathrm{~N} 0 \mathrm{M} 0$

with GC and distant metastases according to up-to-date guidelines [19]. A recent meta-analysis of randomized trials that compared chemotherapy and best supportive care in patients with MGC revealed that chemotherapy was more beneficial than best supportive care alone with respect to OS and quality of life [20]. However, the role of surgery (debulking gastrectomy or gastrectomy plus metastasectomy) in GC patients with distant metastasis is still controversial [2-18]. The results of our study suggest that surgery may be beneficial in MGC patients when combined with chemotherapy.

It is noteworthy that the patients in our study consisted of only stage IV $\left(\mathrm{M}_{1}\right) \mathrm{GC}$ patients who had received chemotherapy. According to the AJCC TNM classification (6th edition), $\mathrm{pN}$ stage was defined by the number of metastatic lymph nodes, and patients with $\mathrm{T}_{4} \mathrm{~N}_{1-2} \mathrm{M}_{0}$ or $\mathrm{T}_{\mathrm{x}} \mathrm{N}_{3} \mathrm{M}_{0}$ were also grouped into stage IV [23]. However, these patients have locoregional tumors and are candidates for curative resection by experienced surgeons. Recent studies in large-volume hospitals in Korea and China have shown clinical and survival differences among subgroups of patients with stage IV GC. Patients with stage IV $\left(\mathrm{M}_{0}\right)$ GC have a longer OS than those with stage IV $\left(\mathrm{M}_{1}\right) \mathrm{GC}$ $[25,26]$. Therefore, we excluded stage IV $\left(\mathrm{M}_{0}\right)$ patients in our study to obtain a more homogeneous group. This unsuitable definition of stage IV in the 6th edition of the AJCC system has recently been changed in the 7 th edition. In the 7 th edition of the AJCC system, stage IV cases are defined as cases with distant metastasis $\left(\mathrm{M}_{1}\right)$ only; cases with $\mathrm{T}_{4} \mathrm{~N}_{1-2} \mathrm{M}_{0}$ or $\mathrm{T}_{\mathrm{x}} \mathrm{N}_{3} \mathrm{M}_{0}$ in the 6th edition are now classified as stage II or III [27]. In addition, we also excluded stage IV $\left(\mathrm{M}_{1}\right) \mathrm{GC}$ patients who had not received systemic chemotherapy. Although systemic chemotherapy is the only proven standard treatment of MGC [19], most previous studies evaluating the benefit of gastrectomy \pm metastasectomy in MGC were performed without considering the influence of chemotherapy. In most previous studies [3-6, 8-18], both patients who had and had not received systemic chemotherapy were included. Therefore, many clinicians have been confused about the results, insisting on the benefits of surgery in stage IV $\left(\mathrm{M}_{1}\right)$ GC, based on results derived from heterogeneous patient populations. However, in our study, by excluding patients who had not received systemic chemotherapy and patients in whom the cancer stage was IV $\left(\mathrm{M}_{0}\right)$, a more homogeneous patient population was obtained.

Many clinicians have concerns about the detrimental effect of surgery in patients with MGC. Even in largevolume centers, palliative gastrectomy has been reported to be associated with high morbidity $(>50 \%)$ and mortality $(6-12 \%)$ [3, 15]. However, some recent studies have shown that the postoperative morbidity and mortality are acceptable, in agreement with our results [9, 28]. In our study, serious postoperative morbidity was uncommon and there was no surgery-related mortality. Therefore, previous studies, as well as the present study, show that gastrectomy \pm metastasectomy can be safely performed at experienced institutes. Additionally, with the exception of 
Table 4 Univariate analysis of prognostic factors for OS

\begin{tabular}{|c|c|c|c|c|}
\hline Variables & $\begin{array}{l}\text { Median } \\
\text { OS } \\
\text { (months) }\end{array}$ & HR & $95 \% \mathrm{CI}$ & $P$ value \\
\hline \multicolumn{5}{|l|}{ Age (years) } \\
\hline$<60$ & 12.0 & 1.00 & - & - \\
\hline$\geq 60$ & 11.2 & 0.97 & $0.74-1.27$ & 0.795 \\
\hline \multicolumn{5}{|l|}{ Gender } \\
\hline Male & 11.4 & 1.00 & - & - \\
\hline Female & 12.1 & 1.01 & $0.76-1.36$ & 0.929 \\
\hline \multicolumn{5}{|l|}{ Performance status } \\
\hline ECOG $0-1$ & 14.0 & 1.00 & - & - \\
\hline ECOG 2 & 7.6 & 1.77 & $1.26-2.49$ & 0.001 \\
\hline ECOG 3-4 & 3.6 & 4.48 & $2.59-7.75$ & $<0.001$ \\
\hline \multicolumn{5}{|l|}{ Primary tumor location } \\
\hline Upper one-third & 16.0 & 0.67 & $0.47-0.95$ & 0.025 \\
\hline Others & 11.2 & 1.00 & - & - \\
\hline \multicolumn{5}{|l|}{ Borrmann type } \\
\hline I & 10.0 & 1.00 & - & - \\
\hline II & 12.9 & 0.98 & $0.39-2.49$ & 0.972 \\
\hline III & 12.0 & 0.85 & $0.37-1.92$ & 0.688 \\
\hline IV & 13.1 & 0.81 & $0.35-1.87$ & 0.614 \\
\hline EGC-like or unclassified & 5.2 & 1.28 & $0.46-3.61$ & 0.638 \\
\hline \multicolumn{5}{|l|}{ Differentiation } \\
\hline $\mathrm{W} / \mathrm{D}$ and $\mathrm{M} / \mathrm{D}$ & 14.2 & 1.00 & - & - \\
\hline $\mathrm{P} / \mathrm{D}$ & 11.8 & 1.22 & $0.86-1.73$ & 0.256 \\
\hline $\mathrm{SRC}$ & 8.9 & 1.31 & $0.87-1.95$ & 0.195 \\
\hline Unclassified & 11.2 & 1.13 & $0.55-2.30$ & 0.744 \\
\hline \multicolumn{5}{|l|}{ Number of involved organs } \\
\hline $0-2$ & 13.1 & 1.00 & - & - \\
\hline $3-5$ & 7.5 & 1.77 & $1.27-2.48$ & 0.001 \\
\hline \multicolumn{5}{|l|}{ Surgical outcome } \\
\hline Group A & 28.0 & 0.25 & $0.15-0.40$ & $<0.001$ \\
\hline Group B & 15.5 & 0.65 & $0.45-0.94$ & 0.022 \\
\hline Group C & 9.0 & 1.00 & - & - \\
\hline
\end{tabular}

$O S$ overall survival, $H R$ hazard ratio, $C I$ confidence interval, $E C O G$ Eastern Cooperative Oncology Group, EGC early gastric cancer, W/D well differentiated adenocarcinoma, $M / D$ moderately differentiated adenocarcinoma, $P / D$ poorly differentiated adenocarcinoma, $S R C$ signet ring cell carcinoma

patients with severe symptoms (obstruction, perforation, or bleeding) directly caused by gastric cancer per se, we considered gastrectomy ( \pm metastasectomy) only in patients with the number of organs involved by GC of $\leq 2$. As we had experienced some GC patients with extensive tumor burdens (i.e., extensive peritoneal or liver metastasis) who could not recover from surgery because of rapid exacerbation of residual tumors during the postoperative period, and thus were not able to receive palliative systemic chemotherapy-the only verified standard treatment for these patients-patients with extensive tumor burdens
Table 5 Multivariate analysis of prognostic factors for OS

\begin{tabular}{llll}
\hline Variables & aHR & $95 \%$ CI & $P$ value \\
\hline Performance status & & & \\
ECOG 0-1 & 1.00 & - & - \\
ECOG 2 & 1.91 & $1.34-2.72$ & $<0.001$ \\
ECOG 3-4 & 3.55 & $2.04-6.17$ & $<0.001$ \\
Primary tumor location & & & \\
$\quad$ Upper one-third & 0.68 & $0.48-0.98$ & 0.038 \\
Others & 1.00 & - & - \\
Number of involved organs & & & - \\
0-2 & 1.00 & - & 0.115 \\
3-5 & 1.33 & $0.93-1.88$ & \\
Surgical outcome & & & $<0.001$ \\
Group A & 0.27 & $0.16-0.45$ & 0.024 \\
Group B & 0.64 & $0.44-0.94$ & - \\
Group C & 1.00 & - & 0 \\
\hline
\end{tabular}

$a H R$ adjusted hazard ratio, ECOG Eastern Cooperative Oncology Group

were not considered as candidates for gastrectomy ( \pm metastasectomy) in our study.

For patients with MGC, the role of debulking gastrectomy remains controversial. Nevertheless, debulking gastrectomy is preferred by some clinicians before the initiation of palliative chemotherapy, even in the absence of any symptoms, such as bleeding and stenosis, based on the results of retrospective studies [11, 13-18]. In our study, patients who had received both debulking gastrectomy and chemotherapy (group B) had a prolonged OS compared to patients who had received chemotherapy alone without debulking gastrectomy (group C) (15.5 vs. 9.0 months; $P=0.022$ ). Our data suggest that debulking gastrectomy may be beneficial in patients with MGC for whom palliative chemotherapy is planned. However, as our study was based on a retrospective analysis, this observation needs to be confirmed in future prospective randomized studies. Recently, a prospective randomized trial (Japan Clinical Oncology Group [JCOG] 0705/ Korea Gastric Cancer Association [KGC] A01) was initiated in Korea and Japan to evaluate the role of debulking gastrectomy in patients with MGC [29]. In the trial, gastrectomy with D1 lymph node dissection is performed without a metastasectomy. This randomized study is expected to reveal the role of debulking gastrectomy in patients with MGC.

In our study, MGC patients who had received both chemotherapy and CGR of the primary plus metastatic sites (group A) had a much longer OS than other patients with MGC (groups B and C). Compared with the very grave survival outcomes (median OS, 9.0 months) in patients who had received palliative chemotherapy alone (group C), the median OS and 3-year survival rate in group A patients 
were 28.0 months and $42.8 \%$, respectively (Fig. 1). Some patients in group A had prolonged disease-free survival without any evidence of tumor recurrence that might lead to cure for some patients with distant metastasis (Table 3). Although the role of metastasectomy is well established in colorectal cancer and sarcoma, it is still controversial whether or not surgery targeting metastatic lesions has beneficial effects for patients with MGC. Some retrospective studies have shown promising results, with a median OS of 11.2-31.0 months, and some non-randomized comparative analyses have suggested survival benefits for aggressive surgical treatment in patients with MGC [4-10]. The results of our study are consistent with previous studies suggesting that gastrectomy plus metastasectomy is beneficial for patients with GC and distant metastases. As in the case of debulking gastrectomy, a patient selection bias might have been involved in our analysis, because patients undergoing surgical resection with the intent of complete resection (group A) had a better PS or less organ involvement by $\mathrm{GC}$ metastasis than patients in group $\mathrm{C}$ (Table 1). We tried to exclude such a bias by adjusting for PS, the number of involved organs, and other clinical parameters in the multivariate analysis, and we showed the consistent survival benefit of gastrectomy plus metastasectomy in the multivariate model (Table 5). Despite this, we cannot help but admit that even such a process cannot completely exclude the inherent biases of a retrospective study. Therefore, as in the case of debulking gastrectomy, our observation of favorable outcomes from gastrectomy plus metastasectomy in MGC patients needs to be further evaluated in large-scale prospective studies.

\section{Conclusion}

Our study suggests beneficial treatment effects from debulking gastrectomy or gastrectomy plus metastasectomy in patients with MGC receiving chemotherapy. Especially, MGC patients who received both chemotherapy and complete tumor resection (gastrectomy plus metastasectomy) had the best survival outcome, with a median OS of 28.0 months, and some of them had long-term survival without tumor recurrence. The perioperative risk of gastrectomy \pm metastasectomy was acceptable. Well-designed prospective trials to determine the role of multidisciplinary approaches combining chemotherapy and surgery in MGC patients are needed to confirm the observations of our study.

\section{References}

1. Parkin DM, Bray F, Ferlay J, Pisani P. Global cancer statistics, 2002. CA Cancer J Clin. 2005;55:74-108.
2. Sarela AI, Yelluri S. Gastric adenocarcinoma with distant metastasis: is gastrectomy necessary? Arch Surg. 2007;142: 143-9. discussion 149.

3. Miner TJ, Jaques DP, Karpeh MS, Brennan MF. Defining palliative surgery in patients receiving noncurative resections for gastric cancer. J Am Coll Surg. 2004;198:1013-21.

4. Cheon SH, Rha SY, Jeung HC, Im CK, Kim SH, Kim HR, et al. Survival benefit of combined curative resection of the stomach (D2 resection) and liver in gastric cancer patients with liver metastases. Ann Oncol. 2008;19:1146-53.

5. Cheong JH, Hyung WJ, Chen J, Kim J, Choi SH, Noh SH. Survival benefit of metastasectomy for Krukenberg tumors from gastric cancer. Gynecol Oncol. 2004;94:477-82.

6. Glehen O, Schreiber V, Cotte E, Sayag-Beaujard AC, Osinsky D, Freyer G, et al. Cytoreductive surgery and intraperitoneal chemohyperthermia for peritoneal carcinomatosis arising from gastric cancer. Arch Surg. 2004;139:20-6.

7. Gold JS, Jaques DP, Bentrem DJ, Shah MA, Tang LH, Brennan MF, et al. Outcome of patients with known metastatic gastric cancer undergoing resection with therapeutic intent. Ann Surg Oncol. 2007;14:365-72.

8. Hall JJ, Loggie BW, Shen P, Beamer S, Douglas Case L, McQuellon R, et al. Cytoreductive surgery with intraperitoneal hyperthermic chemotherapy for advanced gastric cancer. J Gastrointest Surg. 2004;8:454-63.

9. Sakamoto Y, Sano T, Shimada K, Esaki M, Saka M, Fukagawa T, et al. Favorable indications for hepatectomy in patients with liver metastasis from gastric cancer. J Surg Oncol. 2007;95:534-9.

10. Yonemura Y, Kawamura T, Bandou E, Takahashi S, Sawa T, Matsuki N. Treatment of peritoneal dissemination from gastric cancer by peritonectomy and chemohyperthermic peritoneal perfusion. Br J Surg. 2005;92:370-5.

11. Lin SZ, Tong HF, You T, Yu YJ, Wu WJ, Chen C, et al. Palliative gastrectomy and chemotherapy for stage IV gastric cancer. J Cancer Res Clin Oncol. 2008;134:187-92.

12. Lim S, Muhs BE, Marcus SG, Newman E, Berman RS, Hiotis SP. Results following resection for stage IV gastric cancer; are better outcomes observed in selected patient subgroups? J Surg Oncol. 2007;95:118-22.

13. Saidi RF, ReMine SG, Dudrick PS, Hanna NN. Is there a role for palliative gastrectomy in patients with stage IV gastric cancer? World J Surg. 2006;30:21-7.

14. Bonenkamp JJ, Sasako M, Hermans J, van de Velde CJ. Tumor load and surgical palliation in gastric cancer. Hepatogastroenterology. 2001;48:1219-21.

15. Hartgrink HH, Putter H, Klein Kranenbarg E, Bonenkamp JJ, van de Velde CJ. Value of palliative resection in gastric cancer. Br J Surg. 2002;89:1438-43.

16. Kikuchi S, Arai Y, Morise M, Kobayashi N, Tsukamoto H, Shimao H, et al. Gastric cancer with metastases to the distant peritoneum: a 20-year surgical experience. Hepatogastroenterology. 1998;45:1183-8.

17. Maekawa S, Saku M, Maehara Y, Sadanaga N, Ikejiri K, Anai H, et al. Surgical treatment for advanced gastric cancer. Hepatogastroenterology. 1996;43:178-86.

18. Ouchi K, Sugawara T, Ono H, Fujiya T, Kamiyama Y, Kakugawa $\mathrm{Y}$, et al. Therapeutic significance of palliative operations for gastric cancer for survival and quality of life. J Surg Oncol. 1998;69:41-4.

19. Ajani JA, NCCN Panel. National Comprehensive Cancer Network $(\mathrm{NCCN})$ clinical practice guidelines in oncology: gastric cancer (V.2.2010). in ed; 2010.

20. Wagner AD, Grothe W, Haerting J, Kleber G, Grothey A, Fleig WE. Chemotherapy in advanced gastric cancer: a systematic review and meta-analysis based on aggregate data. J Clin Oncol. 2006;24:2903-9. 
21. Choi IS, Oh DY, Kim BS, Lee KW, Kim JH, Lee JS. Oxaliplatin, 5-FU, folinic acid as first-line palliative chemotherapy in elderly patients with metastatic or recurrent gastric cancer. Cancer Res Treat. 2007;39:99-103.

22. Lee KW, Bang SM, Kim S, Lee HJ, Shin DY, Koh Y, et al. The incidence, risk factors and prognostic implications of venous thromboembolism in patients with gastric cancer. J Thromb Haemost. 2010;8:540-7.

23. Greene F, Page D, Fleming I, Fritz A, Balch C, Haller D. AJCC cancer staging manual. 6th ed. New York, NY: Springer-Verlag; 2002.

24. Japanese Research Society for Gastric Cancer. Japanese classification of gastric carcinoma. 1st English edition. Tokyo: Kanehara; 1995.

25. An JY, Ha TK, Noh JH, Sohn TS, Kim S. Proposal to subclassify stage IV gastric cancer into IVA, IVB, and IVM. Arch Surg 2009; 144:38-45; discussion 45.
26. Li C, Yan M, Chen J, Xiang M, Zhu ZG, Lin YZ. Prognostic influence of sub-stages according to pTNM categories in patients with stage IV gastric cancer. J Surg Oncol. 2009;99:324-8.

27. Edge SB, Byrd DR, Carducci MA, et al., editors. American Joint Committee on Cancer (AJCC) Cancer Staging Manual. 7th ed. New York: Springer; 2009.

28. Zacherl J, Zacherl M, Scheuba C, Steininger R, Wenzl E, Muhlbacher F, et al. Analysis of hepatic resection of metastasis originating from gastric adenocarcinoma. J Gastrointest Surg. 2002;6:682-9.

29. Fujitani K, Yang HK, Kurokawa Y, Park DJ, Tsujinaka T, Park $\mathrm{BJ}$, et al. Randomized controlled trial comparing gastrectomy plus chemotherapy with chemotherapy alone in advanced gastric cancer with a single non-curable factor: Japan Clinical Oncology Group Study JCOG 0705 and Korea Gastric Cancer Association Study KGCA01. Jpn J Clin Oncol. 2008;38:504-6. 